\title{
ON THE GEODETIC DATUMS IN SRI LANKA
}

\author{
P.G.V. Abeyratne ${ }^{1}$, W.E. Featherstone ${ }^{2}$ and D.A. Tantrigoda ${ }^{3}$ \\ ${ }^{1}$ Department of Surveying and Geodesy, Faculty of Geomatics, \\ Sabaragamuwa University of Sri Lanka, PO Box 02, Belihuloya, Sri Lanka \\ ${ }^{2}$ Western Australian Centre for Geodesy \& The Institute for Geoscience Research, \\ Curtin University of Technology, GPO Box U1987, Perth, WA 6845, Australia \\ ${ }^{3}$ Department of Physics, University of Sri Jayewardenepura, Nugegoda, Sri Lanka
}

\begin{abstract}
The geodetic datums in Sri Lanka (formerly Ceylon) for latitude and longitude, height and gravity are described and discussed, because this information is not available in the open literature. It is recommended that most of these datums require some upgrading.
\end{abstract}

KEYWORDS: Geodetic datums, coordinates, gravity, Sri Lanka

\section{INTRODUCTION}

Sri Lanka (called Ceylon before 1972) is one of the countries in the world where little information is available in the open literature about its geodetic datums and their development. For instance, NGA [16] and the European Petroleum Survey Group (http://www.epsg.org/) - often considered as definitive sources on geodetic datums only give limited information about Sri Lanka / Ceylon. Therefore, this paper gives a description of the historical development of geodetic datums for latitude, longitude, height and gravity in Sri Lanka, hopefully in a form that should be useful to most practitioners. We point out the peculiarities of the Sri Lankan datums, with a series of recommendations of ways in which they might be upgraded in the future.

\section{KANDAWALA HORIZONTAL GEODETIC DATUM}

The principal triangulation of Ceylon began in 1857 with the measurement of the Negombo (Kandawala to Halgastota) baseline. The triangulation observations were made with 8-inch and 13-inch vernier theodolotes, and were completed in 1885 . This triangulation was subsequently connected to the Indian Triangulation in 1887 by a long narrow triangulation chain running roughly through Batticaloa, Trincomalee, Manar and Delft. The Ceylon network was recomputed with some additional observations in 1890 due to inconsistencies occurring mainly in the minor triangulations. The resulting coordinates were termed "new fixing values" and were thought - at that time - to be satisfactory for the Topographical Survey of Ceylon for which this horizontal geodetic network was originally planned $[\mathbf{1 3}, \mathbf{9}]$.

These "new fixing values" were later found to be in serious error and inconsistent with cadastral surveys, which led to a significant revision of the network [13]. This involved re-measuring the distances and astronomic azimuths of the baselines at Negombo and Batticaloa (Tavelamunai to Vaunativu) with invar tapes and a Gautier 5inch micrometer theodolote. The two baselines were about 5.5 miles (about $8.8 \mathrm{~km}$ ) long and separated by about 127 miles (about $205 \mathrm{~km}$ ). The astronomical coordinates of Kandawala $\left(\Phi=7^{\circ} \mathrm{N} 14^{\prime} 06.8^{\prime \prime} 3,8 \Lambda=79^{\circ} \mathrm{E} 52^{\prime} 36.670^{\prime \prime}\right)$ and the astronomical azimuth $\left(A=176^{\circ} 41^{\prime} 33.18^{\prime}\right)$ of the Negombo baseline were held fixed in the 1930 'readjustment' of geodetic-survey observations collected between 1858 and 1906 at 110 primary control stations to form the Kandawala datum $[\mathbf{1 3}, \mathbf{9}, \mathbf{1 6}]$. It uses the 
Everest 1830 ellipsoid, with the semi-major axis length of $a=6,377,276.345 \mathrm{~m}$ and reciprocal flattening of $1 / f=300.8017$. The coordinate values based on this 1930 'readjustment' were called "new conformal values”.

In the above text, we use inverted commas around the term 'readjustment' of the new conformal values for the Kandawala datum because it was actually carried out as piece-wise continuation of figures, as opposed to an adjustment by least-squares. Initially four figures were selected and 'adjusted' between the Negombo baseline and Pidurutalagala (as the false origin), followed by a total of nineteen other figures [13].

Studies carried out by the Survey Department of Ceylon / Sri Lanka after 1930 with newer technologies were used to assess the reliability of the geodetic network that formed the Kandawala datum. These studies confirmed that the network had to be upgraded so as to be more compatible with cadastral surveys. It was recommended that the network be upgraded to first-order accuracy to provide control for all surveying and mapping purposes, but this did not occur.

A later study of the triangulation networks took place in 1992. The angles at one newly established, 14 replaced destroyed stations and places that were identified as weak stations in the previous studies were measured with a Wild T3 theodolite and distances were measured with MRA7 tellurometer. The angular observations agreed with Jackson [13], but the distances differed by about $3 \mathrm{~m}$ in some places [9]. Also, this new network was least-squares adjusted on the Everest ellipsoid but with a slightly different semi-major axis length $(a=6377299.151 \mathrm{~m})$ and used the same Kandawala astronomical origin point and azimuth. The coordinates from this adjustment are different to Jackson's values, but the reason for selecting a different ellipsoid is not clear, but may be due to a different conversion from imperial feet to metres. No record could be found that any revision was made to Jackson's values as a result of these studies. As such, it is likely that the 1930 Kandawala datum still contains horizontal position errors of a few metres, or maybe more.

Finally, the national map-grid coordinates based on the Kandawala datum use a transverse Mercator projection with the parameters listed in Table 1. The Kandawala datum and associated map grid are still in use in Sri Lanka today, but are used in parallel with the Sri Lankan Datum 1999 (described next).

Table 1. Transverse Mercator projection parameters for the Sri Lankan national map-grid based on the Kandawala datum and using the Everest 1830 ellipsoid

\begin{tabular}{|l|r|}
\hline \multicolumn{1}{|c|}{ parameter } & \multicolumn{1}{c|}{ value } \\
\hline Longitude of origin (central meridian) & $80^{\circ} 46^{\prime} 18.16000^{\prime \prime} \mathrm{E}$ \\
\hline Latitude of origin & $07^{\circ} 00^{\prime} 01.72900^{\prime \prime} \mathrm{N}$ \\
\hline Central scale factor & 0.9999238418 \\
\hline False northing & $200,000.000 \mathrm{~m}$ \\
\hline False easting & $200,000.000 \mathrm{~m}$ \\
\hline Semi-major axis length & $6377276.345 \mathrm{~m}$ \\
\hline Reciprocal flattening & 300.8017 \\
\hline
\end{tabular}

\section{SRI LANKA DATUM 1999 (SLD99)}

In 1993, the Sri Lankan Geodetic Survey Unit (GSU) decided to establish a new Sri Lankan horizontal geodetic control network and thus datum using only GPS [9]. The survey took nearly two years (1996-1998) using five Leica System 300 GPS receivers over 1265 baselines at a typical station spacing of 20-30km, which were least-squares adjusted using Geolab v2.6. This led to the [horizontal] Sri Lanka Datum 1999 (SLD99), which comprises one origin point (ISMD, Institute of Surveying and 
Mapping Diyatalawa), 10 secondary base stations, 48 existing Kandawala triangulation stations, 20 fundamental benchmarks of the Sri Lankan levelling network (described later), and another 194 new stations. All 273 stations were occupied by GPS. SLD99 has a much denser coverage than Kandawala (110 stations), but some gaps remain in SLD99 (Figure 1), which we recommend should be filled.

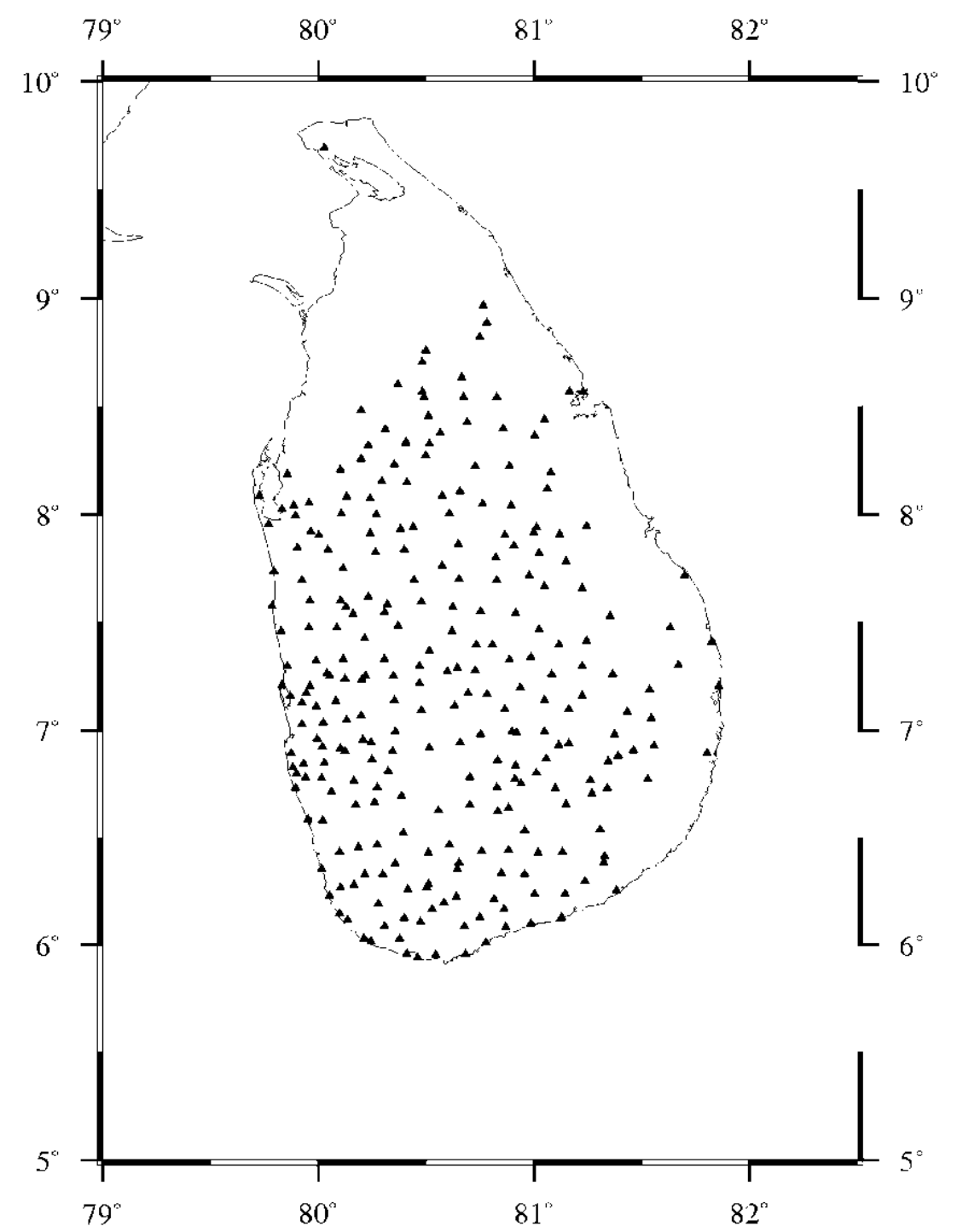

Figure 1. Coverage of GPS control points used to define SLD99 (Mercator projection)

The old Kandawala network was revised and upgraded at the same time as SLD99 by introducing the Euclidean distances determined from the GPS baseline vectors observed between its triangulation stations. The least-squares readjustment was carried out on the Everest 1830 ellipsoid. This is the reason for the slightly different values for the central meridian, which passes through Pidurutalagala (cf. Tables 1 and 2). There were 48 common stations in the new SLD99 network and the upgraded Kandawala network, which were used to determine datum transformation parameters (given later). Hence, SLD99 is defined via a transformation and is thus not geocentric.

SLD99 was made available for use in Sri Lanka since 2000. The national map-grid coordinates, termed SL_GRID_99, are computed using a transverse Mercator projection on the Everest 1830 ellipsoid (Table 2). Both Kandawala and SLD99 are used in parallel. The difference between the false origins of the respective grid coordinates (cf. Tables 1 and 2) means that the two can be distinguished apart. 
Table 2. Transverse Mercator projection parameters for the Sri Lankan SL_GRID_99 based on the SLD99 and using the Everest 1830 ellipsoid

\begin{tabular}{|l|r|}
\hline \multicolumn{1}{|c|}{ parameter } & \multicolumn{1}{c|}{ value } \\
\hline Longitude of the central meridian & $80^{\circ} 46^{\prime} 18.16710^{\prime \prime} \mathrm{E}$ \\
\hline Latitude of origin & $07^{\circ} 00^{\prime} 01.69750 " \mathrm{~N}$ \\
\hline Central scale factor & 0.9999238418 \\
\hline False northing & $500,000.000 \mathrm{~m}$ \\
\hline False easting & $500,000.000 \mathrm{~m}$ \\
\hline Semi-major axis & $6377276.345 \mathrm{~m}$ \\
\hline Reciprocal flattening & 300.8017 \\
\hline
\end{tabular}

\section{PECULIARITIES OF SLD99}

As part of an evaluation of the EGM2008 global gravity field model [17], we [1] discovered a significant bias of $-1.752 \mathrm{~m}$ (standard deviation of $\pm 0.184 \mathrm{~m}$ ) during comparisons with GPS-levelling in Sri Lanka after rejection of outliers. Since the mean sea level-based spirit-levelled Sri Lankan height datum (described later) could not reasonably account for this bias, we focussed on the GPS ellipsoidal height datum. This led to the discovery of some peculiarities in the realisation of SLD99, as follows.

\section{Origin Point}

From [9], the coordinates of SLD99's origin point at ISMD were determined from two GPS baselines to the DORIS (Doppler Orbit Determination and Radiopositioning Integrated on Satellite) station at the Surveyor General's Office (SGO) in Colombo (COLA; DOMES ID 23501S001), which was active from 1991 to 2004. Since the ground mark beneath the $~ 3-m-h i g h$ DORIS beacon could not be occupied by GPS, GSU [9] occupied a 'GPS marker' nearby (DOMES ID: 23501M001) listed at the IDS (International DORIS Service) website (http://ids.cls.fr/), to differentially determine the geocentric coordinates of the origin point at ISMD.

As a first problem with the realisation of SLD99, COLA has since been identified as one of 17 stations with poor antenna stability [6] and was not recommended [23] for the DORIS core network in ITRF2005 [2]. As such, the base-station coordinates for the differential GPS baseline to ISMD may not be as precise as they might be.

The site-log for COLA at the IDS website gives the 3D tie vector between the DORIS ground marker and the 'GPS marker' used by GSU. This 'GPS marker' was local-tied to COLA during the Epoch'92 IGS GPS campaign by IGN (Institut Géographique National, France) using a total station (H. Fagard 2008, pers. comm.). However, the coordinates of the GPS marker used by [9] are not the same as the DOMES 'GPS marker' (Table 3). From recent communications with staff at the GSU, the 'GPS marker' is physically the same point, but the coordinates have been used inaccurately for the differential GPS survey to position ISMD.

Table 3. Coordinates adopted for the DOMES 23501M001GPS marker

\begin{tabular}{|l|r|r|r|}
\hline \multicolumn{1}{|c|}{ coordinate } & \multicolumn{1}{c|}{ IDS values } & \multicolumn{1}{c|}{ SGO values } & $\mid$ difference $\mid$ \\
\hline Longitude & $79^{\circ} 52^{\prime} 26.314640 " \mathrm{E}$ & $79^{\circ} 52^{\prime} 26.3102^{\prime \prime} \mathrm{E}$ & $0.004440^{\prime \prime}(0.137 \mathrm{~m})$ \\
\hline Latitude & $06^{\circ} 53^{\prime} 30.861133^{\prime \prime} \mathrm{N}$ & $06^{\circ} 53^{\prime} 30.8699^{\prime \prime} \mathrm{N}$ & $0.008767^{\prime \prime}(0.270 \mathrm{~m})$ \\
\hline Ellip. height & $-75.692 \mathrm{~m}$ & $-76.238 \mathrm{~m}$ & $0.454 \mathrm{~m}$ \\
\hline
\end{tabular}

The uncertainty in the SLD99 origin point is compounded further by the methodology used to determine the coordinates of ISMD, which is approximately 120 
$\mathrm{km}$ east of the 'GPS marker' at COLA. Two single GPS baselines (i.e., radiations) were used over an ellipsoidal height difference of about $1.2 \mathrm{~km}$ [9]. These baselines were processed with Leica SKI v2.1 software. However, differential tropospheric delays in this near-equatorial region are usually poorly modelled by commercial GPS software in single baseline mode, resulting in positional error, mainly in height [20]. Also, this survey was conducted in 1996, which is a time when GPS selective availability was active.

The origin coordinates at ISMD used for SLD99 were obtained from the mean of the differential GPS baseline solutions with respect to the DORIS 'GPS marker' at COLA ( $80^{\circ} 57^{\prime} 40.88000^{\prime \prime}$ E, 06 49' 02.68716" N, $h=1164.366 \mathrm{~m}$ ). Since SLD99 has not been connected properly to the ITRF, we recommend that a re-observation of the COLA-ISMD baseline or reprocessing of the original data with the correct coordinates for the 'GPS marker' would deliver more reliable geocentric coordinates for ISMD.

\section{Network Adjustments}

The GPS network for SLD99 was established in what could be considered as more of a 'traditional' geodetic-survey way, where 10 secondary base stations were connected to ISMD with 46 GPS baselines; further densification surveys were used to establish the additional 262 stations. By 'traditional', we mean that higher order control stations are supplemented by in-fill by lower order stations and so on. Unfortunately, no information is available in [9] on the GPS baseline processing statistics, such as whether the integer ambiguities were fixed. Moreover, the network adjustment strategy documented in [9] is not optimal, as follows.

Geolab v2.6 was used to least-squares adjust the GPS baseline vectors and their variance-covariance matrices, but this was done in a staged process. The 10 secondary stations were adjusted with a 3D minimal constraint at ISMD (recall that the coordinates of this origin point are in question), then the remaining baselines were adjusted by holding ISMD and these 10 stations fixed (actually, very tightly constrained). That is, the network could become distorted if the coordinates of two or more points have been kept 'fixed' to incorrect values. As such, the normal equations lead to an adjustment solution that is biased towards the 'fixed' coordinates [e.g., 4].

In the case of SLD99, the initial network adjustments of these 10 secondary base stations and remaining 1,265 baselines did not provide 'good' a posteriori statistics [9], so the computed Euclidean baseline distances from the GPS baseline vectors were added to the adjustment. This strategy leads to a poorly designed adjustment model, which is not the general practice of a least-squares adjustment of geodetic data. Simply, computed values should not be mixed with observed values, especially when the computed values come from the same observed values. Simply, it adds unreal redundancy that the least-squares adjustment will misinterpret.

Inspecting the appendices in [9], these later adjustments provided improved statistical measures, as would be expected, but which are misleading. The average precision of the 1,265 baselines in the network was just under $0.13 \mathrm{ppm}$. Moreover, these later adjustments still contained numerous flagged residuals. A network adjustment can only be considered successful if no outliers remain (as well as a sigmazero close to unity that passes a statistical test), which was not the case. There is also no mention of what centring errors were used in any adjustment. Since the above precision estimates are not based on a valid least-squares adjustment, we recommend a readjustment of the network.

\section{SLD99 Realisation by Transformation}

A seven-parameter conformal datum transformation was used to realise the 
coordinates adopted for SLD99, using the Everest 1830 ellipsoid, from the GPS coordinates, which are termed WGS84 in Sri Lankan literature [9]. This designation is not strictly correct, since true WGS84 coordinates are not readily available to non-USmilitary, and the Sri Lankan realisation of WGS84 is indirect and through the incorrectly adopted COLA station (described above). As such, we term it WGS84(SL) to show they are strictly not the same datum.

Finally, SLD99 is a local geodetic datum established by GPS, but is not optimal for the reasons outlined above. As such, we recommend that the already-collected data are reprocessed and readjusted differently so as to establish a truly geocentric datum, or even a local datum based on somewhat sounder geodetic principles. Nevertheless, the GPS surveys, albeit not perfect, in SLD99 will have improved upon the Kandawala datum, so we recommend that this datum be used in preference in the interim.

\section{HORIZONTAL DATUM TRANSFORMATION PARAMETERS}

NGA [16] provide transformation parameters from WGS84 to Kandawala for the standard Molodensky transformation model, listed in Table 5 together with parameters for the seven-parameter transformation model from [9]. The NGA parameters were derived from only three stations in Sri Lanka [16]. The GSU parameters were derived from 32 (WGS84(SL) from/to Kandawala) and 58 (WGS84(SL) from/to SLD99) common points across Sri Lanka.

Table 4. Transformation parameters from WGS84 to Sri Lankan horizontal geodetic datums. Values in parentheses are the RMS (one sigma) of the estimated parameters.

\begin{tabular}{|l|r|r|r|}
\hline & \multicolumn{1}{|c|}{$\begin{array}{c}\text { WGS84 to } \\
\text { Kandawala [17] }\end{array}$} & $\begin{array}{c}\text { WGS84(SL) to } \\
\text { Kandawala [10] }\end{array}$ & \multicolumn{1}{c|}{$\begin{array}{c}\text { WGS84(SL) to } \\
\text { SLD99 [10] }\end{array}$} \\
\hline Shift $d X(\mathrm{~m})$ & $97( \pm 20)$ & $18.072( \pm 28.2143)$ & $0.293( \pm 10.7765)$ \\
\hline Shift $d Y(\mathrm{~m})$ & $-787( \pm 20)$ & $-859.123( \pm 12.3905)$ & $-766.950( \pm 5.3273)$ \\
\hline Shift $d Z(\mathrm{~m})$ & $-86( \pm 20)$ & $-92.271( \pm 13.1761)$ & $-87.713( \pm 6.0293)$ \\
\hline $\begin{array}{l}\text { Rotation } \\
\text { about } X(")\end{array}$ & $\mathrm{n} / \mathrm{a}$ & $-0.163409( \pm 0.4219)$ & $0.195704( \pm 0.1930)$ \\
\hline $\begin{array}{l}\text { Rotation } \\
\text { about } Y(")\end{array}$ & $\mathrm{n} / \mathrm{a}$ & $-1.485284( \pm 0.3988)$ & $1.695068( \pm 0.1736)$ \\
\hline $\begin{array}{l}\text { Rotation } \\
\text { about } Z(")\end{array}$ & $\mathrm{n} / \mathrm{a}$ & $1.986825( \pm 0.9153)$ & $3.473016( \pm 0.3490)$ \\
\hline Scale $(\mathrm{ppm})$ & $\mathrm{n} / \mathrm{a}$ & $13.794405( \pm 1.8380)$ & $0.039338( \pm 0.8051)$ \\
\hline Delta $a(\mathrm{~m})$ & -860.655 & $\mathrm{n} / \mathrm{a}$ & $\mathrm{n} / \mathrm{a}$ \\
\hline Delta $f$ & $-0.28361368 \times 10^{4}$ & $\mathrm{n} / \mathrm{a}$ & $\mathrm{n} / \mathrm{a}$ \\
\hline
\end{tabular}

Table 5. Sample transformations from 'WGS84' to Sri Lankan horizontal geodetic datums for a WGS84 coordinate 8N, 80E.

\begin{tabular}{|l|r|r|r|}
\hline & $\begin{array}{c}\text { WGS84 to } \\
\text { Kandawala [17] }\end{array}$ & $\begin{array}{c}\text { WGS84(SL) to } \\
\text { Kandawala [10] }\end{array}$ & \multicolumn{1}{c|}{$\begin{array}{c}\text { WGS84(SL) to } \\
\text { SLD99 [10] }\end{array}$} \\
\hline Lon & $79^{\circ} 59^{\prime} 52.41700^{\prime \prime} \mathrm{E}$ & $79^{\circ} 59^{\prime} 52.32700^{\prime \prime} \mathrm{E}$ & $79^{\circ} 59^{\prime} 52.40545^{\prime \prime} \mathrm{E}$ \\
\hline Lat & $7^{\circ} 59^{\prime} 59.01915^{\prime \prime} \mathrm{N}$ & $8^{\circ} 00^{\prime} 00.09188^{\prime \prime} \mathrm{N}$ & $7^{\circ} 59^{\prime} 59.05283^{\prime \prime} \mathrm{N}$ \\
\hline $\mathrm{E}(\mathrm{m})$ & 114707.305 & 114704.611 & 414706.736 \\
\hline $\mathrm{N}(\mathrm{m})$ & 310572.937 & 310605.895 & 610574.940 \\
\hline
\end{tabular}

The relatively large scale parameter in Table 4 for the WGS84(SL) to Kandawala transformation reflects the distortions in the Kandawala datum that were identified by Jackson [13] and subsequent surveys (described earlier). As such, the transformation 
between WGS84(SL) and Kandawala is not used for this reason. Table 5 gives worked examples of transformed and map-projected coordinates from 'WGS84' to the Sri Lankan datums using the parameters in Tables 1, 2 and 4. This information may be of use to practitioners who wish to test their software before operating in Sri Lanka.

\section{SRI LANKA’S VERTICAL DATUM}

\section{Spirit-levelling Observations}

The vertical geodetic control network of Sri Lanka (originally termed the geodetic levelling of Ceylon [19]) was established between 1926 and 1930 from measurements with parallel glass plate micrometer attachments mounted on precise levels with staves graduated to fiftieths of an imperial foot on a strip of invar fixed at one end. The main part of the levelling network comprised 27 two-way circuits of about 2,400 miles (about 4,300 km) in total (Figure 2). Originally, there were 53 FBMs, though many have been destroyed or disturbed since. The stated precision of the spirit levelling [19] was $\pm 0.42 \mathrm{~mm} / \mathrm{km}$ and the accuracy of determination is $\pm 0.0005 \mathrm{ft}(\sim \pm 0.02 \mathrm{~mm})$. However, these are for spirit-levelling conducted over 70 years ago, so this estimate is very probably over optimistic.

\section{Vertical Datum Origin}

Tidal observations of mean sea level (MSL) were carried out between 1923 and 1933 at two harbours, Colombo and Trincomalee (cf. Figure 2), using self-recording tide gauges, with the aim of defining the Sri Lankan vertical datum's origin point. Beforehand, however, MSL was determined at three harbours by the Trigonometric Survey of India using self-recording tide gauges over the following periods: at Colombo and Galle 1884-1889; and at Trincomalee 1889-1896 [15].

It was originally planned that the Sri Lankan levelling network adjustment would be fixed to zero height at Colombo and Trincomalee, with a later redetermination of the MSL by the newer observations. However, since the tidal observations were underway at Colombo and Trincomalee when the levelling network was adjusted in 1932, MSL at Colombo - as determined by the Great Trigonometric Survey of India during 1884-1889 - was used instead as a minimal constraint.

After the local tidal observations were completed at Colombo and Trincomalee during 1929-1933, a small rise of MSL relative to the tide gauge of $0.074 \mathrm{ft}$ (about $0.023 \mathrm{~m}$ ) at Colombo and $0.199 \mathrm{ft}$ (about $0.061 \mathrm{~m}$ ) at Trincomalee relative to the 18841889 and 1889-1896 values was observed $[\mathbf{1 9}, \mathbf{1 4}]$. Assuming a linear rate of sea level rise relative to the land, and that the tide gauges were stable, yields $+0.52 \mathrm{~mm} /$ year for Colombo and $+1.58 \mathrm{~mm} /$ year for Trincomalee. However, these values should be treated with caution in the context of environmental change because the veracity of these tide gauges cannot be determined.

\section{Height System}

Corrections were applied to the spirit-levelled height differences to account for the non-parallelism of level surfaces of the gravity field using $-0.005302(\Delta \phi) H \sin 2 \phi_{M} \mathrm{ft}$ [3], where $H$ is the mean height of the section of levelling, $\phi_{M}$ is the mean latitude and $\Delta \phi$ is the difference of the latitude of the terminal points of the levelling section. Since these corrections were computed with a normal gravity field, it is more appropriate to say that the Sri Lankan heights are based on a normal-orthometric height system. However, almost every user of heights in Sri Lanka has used the 
terminology of orthometric height (e.g., $[\mathbf{1 9}, \mathbf{2 0}, \mathbf{1 0}]$ ), but this is also the case in many other countries (cf. [9]).

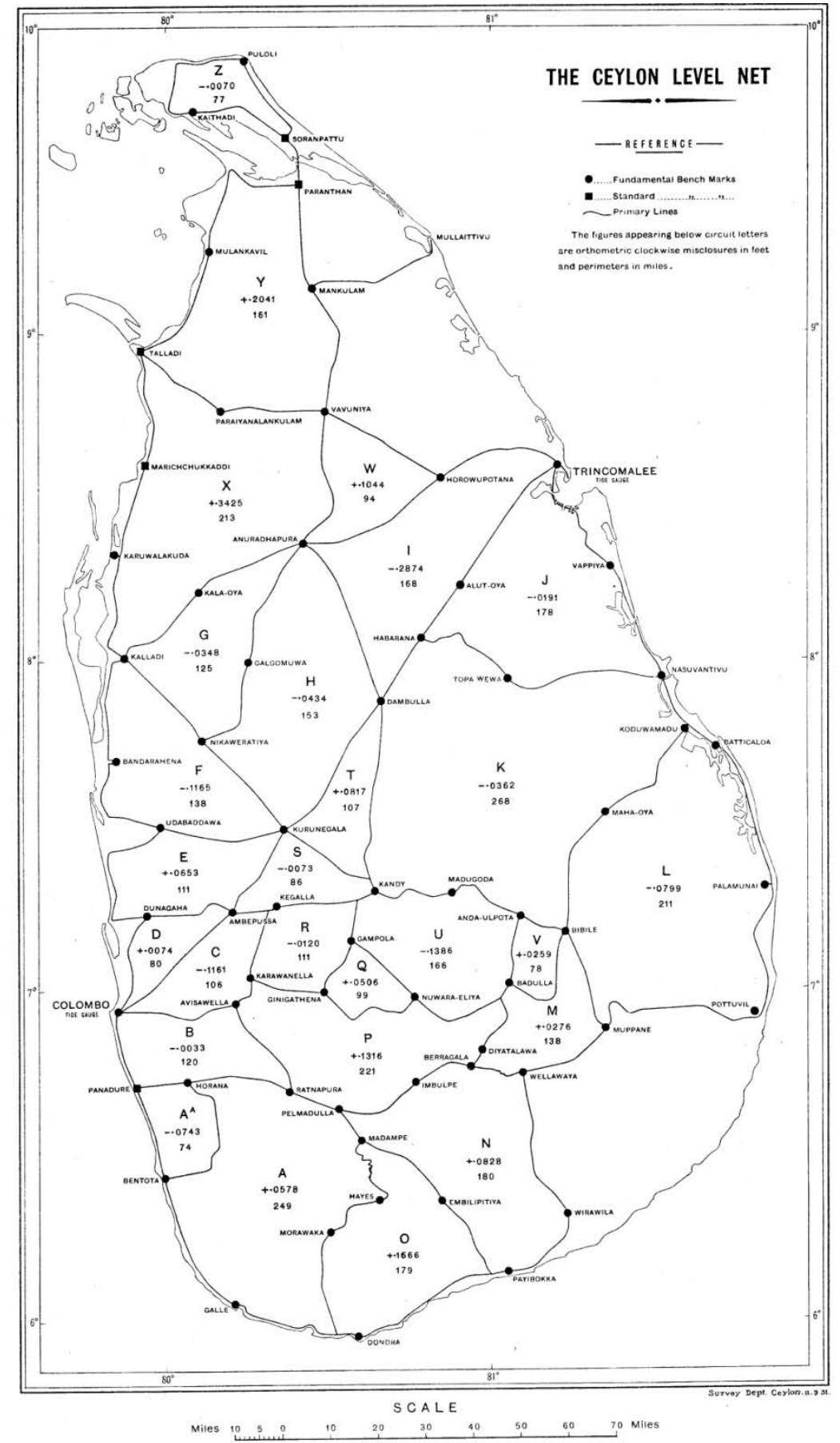

Fig 2. Spirit-levelling lines used to define the Sri Lankan vertical datum (from [19])

\section{GRAVITY DATUMS}

The first published gravity observations in Sri Lanka / Ceylon were made by Glennie [11], of the Survey of India, which involved a set of 21 pendulum gravity observations. These observations resulted in two map compilations showing Hayford anomalies and so-called 'crustal warp' anomalies [12]. The definition of 'crustal warp' anomalies could not be found, but it is possible they are isostatic gravity 
anomalies subject to the theories used at that time. However, the original data are not available to allow any further investigation.

There were several later gravity surveys to connect Sri Lanka to international gravity networks. Relative observations were made at two airports, Ratmalana (Colombo) and Katunayake. [24] made observations at Ratmalana airport, giving a value of $978132.3 \mathrm{mGal}$. Gravity observations at both airports were made again in 1969 when the British Institute of Geological Sciences used a LaCoste \& Romberg (L\&R) gravimeter (serial number G97) to give gravity differences among New Delhi, Yangon (Rangoon), Singapore and Colombo.

The gravity difference between Singapore University’s Geography Department and Katunayake airport was $40.78 \mathrm{mGal}$, and between Singapore and Ratmalana airport was $50.14 \mathrm{mGal}$. Therefore, the gravity values were assigned $978122.24 \mathrm{mGal}$ at Katunayake and 978131.6 mGal at Ratmalana based on the Singapore value of 978081.5 mGal [12], which was based on the Potsdam gravity datum (J Mäkinen, 2008 pers. comm.). These two Potsdam-related gravity values were referred as Evans's values in subsequent Sri Lankan gravity surveys $[\mathbf{1 3}, \mathbf{2 2}]$. As such, Sri Lankan gravity data are offset from IGSN71 [16] by around 14 mGal, originating from Potsdam.

Another control gravity survey was carried out in 1973 by Evans (in an appendix to [12]) using the same G97 L\&R meter at the base stations occupied by [13] and connected to Evans’s 1969 value $(978131.6 \mathrm{mGal})$ at Ratmalana airport. An IGSN71 gravity value at Ratmalana was later calculated by using the IGSN71-derived calibration factor for the L\&R G97 difference measured between the same Singapore and Ratmalana points in 1969. The IGSN71 value at Ratmalana is $978116.81 \mathrm{mGal}$ based on the IGSN71 value (978066.68 mGal) at Singapore University [12].

Ratmalana airport has also been tied to IGSN71 by NAVOCEANO (formerly the U.S. Naval Oceanographic Office), giving the value of $978116.900 \mathrm{mGal}$. While this point was also located at Ratmalana, it is not at the same ground mark observed by Evans in 1969. As such, the Sri Lankan gravity datum is still based on Potsdam, even though IGSN71 values are available. This gives a bias of around $14 \mathrm{mGal}$ between Sri Lankan gravity anomalies and any other gravity anomalies referred to IGSN71 (cf. [1]). As such, it is recommended that the Sri Lankan gravity datum be connected to IGSN71, which might require some new observations, but perhaps only with relative gravimeters.

\section{SUMMARY AND RECOMMENDATIONS}

We have summarised and discussed the development of geodetic datums for latitude, longitude, height and gravity in Sri Lanka, hopefully in a form that will be of use to most practitioners. Our key findings and recommendations/suggestions are:

- The Kandawala horizontal geodetic datum for latitude and longitude contains some significant distortions (3 m or more [9]), but some of the later surveys did not lead to any upgrade [9]. The Kandawala datum was 'supplemented' by the SLD99 datum after 2000, though both datums are still used in parallel and both use the Everest 1830 ellipsoid. Confusion between them may be reduced by different false origin coordinates for their respective map-grid coordinates.

- The ISMD origin point, GPS surveys and network adjustments used to form SLD99 are not optimal and have been questioned here, so it is likely that errors remain in this newer datum, especially regarding geocentricity and the veracity of the least-squares adjustments. However, SLD99 is probably an improvement upon the original Kandawala datum, especially given the large distortions in Kandawala [9]. As such, we [cautiously] recommend that SLD99 be used in preference to Kandawala. 
- $\quad$ The GPS data processing and network adjustment strategies used to form SLD99 should be re-examined, possibly with a view to Sri Lanka adopting a geocentric datum. However, since the geoid-ellipsoid separation over Sri Lanka is very large and undulates rapidly, this would involve more involved terrestrial survey data reduction to a geocentric datum for land surveyors (cf. $[7,8])$, who in Sri Lanka do not routinely have access to expensive geodetic GPS equipment.

- The use of only a seven-parameter transformation model among all these datums, especially Kandawala because of its large distortions, is not recommended. Instead, a transformation model that also accounts for the distortions among the datums is preferable, but this may prove somewhat problematic because of the small number of common points in each datum. Nevertheless, these alternatives should be explored as to their feasibility.

- The Sri Lankan vertical datum is based on five years of MSL observations at Colombo and an approximation of the normal-orthometric height system applied over about 4,300 km of spirit levelling. We recommend that the height system is more clearly defined as a normal-orthometric height system.

- The Sri Lankan gravity datum is still based on Potsdam, and hence so is most of the gravity used there (cf. [1]). Potsdam is known to contain a bias of around 14 mGal compared to IGSN1971 [15]. We recommend that this connection can be achieved relatively easily with a relative gravimeter, but only if the ground monuments remain.

\section{ACKNOWLEDGEMENTS}

PGVA would like to acknowledge funding from Endeavour Research Grant 673_2008 and thanks the Department of Spatial Sciences, Curtin University of Technology, for providing all the facilities and their hospitality. Special thanks go to B.J.P. Mendis (Surveyor General, Survey Department, Colombo, Sri Lanka), J. Mäkinen (Finnish Geodetic Institute, Masala, Finland), H. Fagard (Institut Géographique National, Paris, France) and M. Phillips (Survey Review). We also thank the two detailed and very constructive reviewers of this manuscript, particularly 'reviewer 2'. WEF acknowledges funding by Australian Research Council grant DP0663020. This is TIGeR publication number 203.

\section{References}

1. Abeyratne, P.G.V. and W.E. Featherstone (2009) Assessment of EGM2008 over Sri Lanka, an area where 'fill-in' data were used in EGM2008, Newton's Bulletin 4: 284316.

2. Altamimi Z, Collilieux X, Legrand J, Garayt B, Boucher C (2007) ITRF2005: A new release of the International Terrestrial Reference Frame based on time series of station positions and Earth Orientation Parameters, Journal of Geophysical Research 112, B09401, doi:10.1029/2007JB004949.

3. Bomford G (1971) Geodesy, Third edition, Oxford University Press, Oxford

4. Cepek A, Pytel J (2005) A progress report of numerical solutions of least squares adjustment in GNU Project Gama, Acta Polytechnica 45(1): 12-18.

5. Fagard H (2006) Twenty years of evolution for the DORIS permanent network: from its initial deployment to its renovation, Journal of Geodesy 80(8-11):429-456, doi: 10.1007/s00190-006-0084-2

6. Featherstone WE (1997) The importance of including the geoid in terrestrial survey data reduction to the Geocentric Datum of Australia, The Australian Surveyor 42(1): 45-50.

7. Featherstone WE, Rüeger JM (2000) The importance of using deviations of the vertical in the reduction of terrestrial survey data to a geocentric datum, The TransTasman Surveyor 1(3): 46-61. [Erratum in The Australian Surveyor 47(1): 7] 
8. Featherstone WE, Kuhn M (2006) Height systems and vertical datums: a review in the Australian context, Journal of Spatial Science 51(1): 21-42.

9. Geodetic Survey Unit (2000) Report on Sri Lankan Datum 1999, Survey Department, Colombo

10. Glennie EA (1935) Geodetic Report 1934, Survey of India, Dehra Dun.

11. Hatherton T, Pattaratchi DB, Ranasinghe VVC (1975) Gravity Map of Sri Lanka, 1: 1,000,000 with an appendix by Evans RB, Professional paper No. 3, Sri Lanka Geological Survey Department, Colombo

12. Hatherton T, Ranasinghe VVC (1972) Provisional Bouguer anomaly map of Ceylon, Report No. 72, GNS Science, New Zealand

13. Jackson JE (1933) Re-computation of the principal triangulation, Surveyor General's Office, Colombo

14. Jackson JE (1936) Tidal Observation of Ceylon, Empire Survey Review 20(III): 325334

15. Morelli C, Gantar C, Honkaslo T, Mcconnell RK, Tanner TG, Szabo B, Uotila U, Whalen CT (1974) The International Gravity Standardisation Network 1971 (IGSN71), Special Publication 4 of Bulletin Géodésique, IAG, Paris

16. NGA (2004) Department of Defence World Geodetic System 1984: Its definition and relationship with local geodetic systems, Technical Report TR8350.2, National Geospatial-intelligence Agency, Maryland, USA; http://earthinfo.nga.mil/GandG/publications/tr8350.2/wgs84fin.pdf

17. Pavlis NK, Holmes SA, Kenyon SC, Factor JK (2008) An Earth Gravitational Model to Degree 2160: EGM2008. Presented at the 2008 General Assembly of the European Geosciences Union, Vienna, Austria, April 13-18, 2008

18. Price TY (1932) Geodetic Levelling of Ceylon, Empire Survey Review 5(I): 220-229

19. Price TY, Grice AL (1932) The Geodetic Levelling of Ceylon (1926 - 1929) Vol I. Survey Department, Ceylon

20. Rothacher M (2002) Estimation of station heights with GPS, in: Drewes H, Dodson A, Fortes LPS, Sanchez L and Sandoval P (Eds.), Vertical Reference Systems, Springer, Berlin Heidelberg New York, pp 81-90

21. Udayakantha, PMP, Tennakone TMPUK (1993) Report on gravity control surveys and adjustment of gravity observations, Geodetic Survey Unit, Institute of Surveying and Mapping, Diyatalawa

22. Willis P, Soudarin L, Fagard H, Ries J, Noomen R (2005) IDS recommendations for ITRF2004, IDS Central Bureau Report, International DORIS Service, http://ids.cls.fr/documents/report/IDS_for_ITRF2004_v1_0.pdf

23. Woolard GP, Rose JC (1963) International gravity measurements, Society of Exploration Geophysics, Tulsa. 